\title{
EAGRO - WEB APPLICATION FOR AGRICULTURE
}

\author{
Ana Vesić, \\ Sava Lakićević, \\ Bojan Gutić, \\ Vuk Ignjatović, \\ Miodrag Živković*
}

Singidunum University,

Belgrade, Serbia
Correspondence:

Miodrag Živković

e-mail:

mzivkovic@singidunum.ac.rs

\begin{abstract}
:
The main idea of this project is to adapt to the current state of agriculture in Serbia. Animal abuse, usage of dangerous pesticides and global warming have become more evident than ever through new studies and subsequent documentaries. This has sparked a new wave of regulations and laws, as well as a new trend of organic food and a greater need for sustainability. People still often operate in the gray area of the law and corporations are known to take advantage of farmers. The goal of this project is to provide people with a platform that could help people put themselves on the map, promote communities of farmers and protect the interests of all members in the industry, from the producers to the consumers. Furthermore, this project serves as a way to adapt new trends and satisfy new customer demands. This document contains the purpose, the scope and the design of the project. In addition, this document includes the execution, current progress and the plan for finishing the task at hand.
\end{abstract}

\section{Keywords:}

agriculture, e-governance, platform, web.

\section{INTRODUCTION}

When given the opportunity to work on a project with a mentor, we were motivated to take it upon ourselves to do something truly useful and meaningful. Taking into consideration that agriculture is one of the most important branches of economy, we decided to research the difficulties the government and the agriculturists face in Serbia with the goal of finding solutions. These solutions are in accordance with the plan of technological development in Serbia. In addition to studying the steps taken by the Serbian government, we also studied what other countries have done with an introduction of e-governance. Subsequently, we decided to construct a project around solutions for challenges in Serbia, composed in part by necessary improvements yet to be implemented in this country. These solutions will be implemented into a web application by providing a variety of types of user profiles, by advertising users' offers, demands and organized events and by grouping and analyzing data, intended to increase the quality of user experience. As mentioned previously, this project is also intended for governing bodies. This will give our application two different sides: one oriented at trade and one oriented at e-governance. 
The part of the project aimed at trade and its participants - farmers, buyers, suppliers, resellers and communities - has the goal of simplifying communication between affiliates, serve as a facilitator for trade, induce education and improve development in this branch of economy/government. Another objective is encouraging and promoting event organizations, such as fairs and festivals, with the idea of preserving local traditions, allowing self-promotion and further strengthening local communities. This has the intention to fuel the growth and expansion of the agricultural lifestyle of Serbia. We intend to give members of agriculture this platform that would serve as a stepping stone and additional space to advertise their manifestations. These functionalities of our web application will enable creation of new communities, improve communication between the farmers themselves and respectful governing bodies, and interconnect communities. However, we intend to have this project create a favorable environment for new and old businesses. Providing the ability to advertise and sell online, as well as having the website in multiple languages, will allow putting people on the map for foreign markets.

For the part of the project oriented around e-governance, we have implemented the requirement to provide detailed information during the creation of a new profile. This will form new databases, with data about ownership, scale and type of production, specifications put in place, owned certificates. This will additionally create a detailed map of Serbian agricultural communities and farms. In addition, we aim to add already implemented solutions in the domestic market, like weather forecasts, education on crop production, recommended fertilizers, advertising competitions and fairs, as well as information on how to more easily get certificates, licenses and any sort of necessary documents.

\section{BACKGROUND}

Considering the growing need for digitalization, global trends, and ever-evolving government plans due to EU requirements, we had a look at what branch was most in need of digitalized aid to be able to increase its performance. Accordingly, we took into consideration what Serbia's biggest attribute to its economy is, and what difficulties it faces. We decided to take a closer look into what is specifically being done on the foreign markets and their e-governance plans, as well as our own national plans. The following analysis and research were carried out by analyzing concrete resolutions to given problems in various countries. We followed the myriad solutions offered over the course of several years, the political trends and decisions that accompanied them, as well as the results that they gave, and the future plans that they have now.

There are many worldwide organizations that support the development of IT in agriculture. Their support includes everything from providing concrete solutions and new machinery, to organizing governmental procedures and tasks in favor of the manufacturers and other stakeholders, to protecting people's rights and promoting healthy lifestyles. One of these organizations is Momagri, which was founded in December 2005, "to provide objective analyses and concrete solutions to current and future key international agricultural issues". It advocates a global agricultural governance system that reconciles free trade and regulation. The reason that this organization is of big importance is that it is being referred to in many other documents and statements. Its goals are those of the future, what everyone is aiming for, e.g.: "They aim to provide an institutional framework and economic regulation tools that encourage international cooperation." [1] "Development of trade when it contributes to improving the condition of all farmers, particularly in developing countries, and optimizing supply security for all countries."[2]

In addition to Momagri, there is Map of Ag, which is based in New Zealand but do work for and on a global scale. It enables users to enter the required data to have all of the variables calculated and well presented in order to make a business decision. It is specifically tailored for agriculture. "It has pioneered predictive marketing in agriculture. We use state of the art data modelling and analytics to create insights for our clients and agriculture industry as a whole" [3]. On a smaller scale, but equally significant, are the world-trend affecting policies that are spearheaded by the EU. CAP, or the Common Agricultural Policy, has been around since 1962. Its main goals today are "fostering knowledge transfer and innovation in agriculture, forestry and rural areas, enhancing the viability and competitiveness of all types of agriculture, and promoting innovative farm technologies and sustainable forest management, promoting food chain organization, animal welfare and risk management in agriculture, restoring, preserving and enhancing ecosystems related to agriculture and forestry, promoting resource efficiency and supporting the shift toward a low-carbon and climate-resilient economy in the agriculture, food and forestry sectors, promoting social inclusion, poverty reduction and economic development in rural areas." [4] This project is the EU's largest investment, and has re- 
ceived a lot of attention and funding. It is important, not only for making policies within the EU and acting accordingly, but for applying them in the countries that are in the process of negotiating their future integration.

What is also receiving attention as a big asset provided to the users is the management of businesses, including risk calculations, trends, predictions, statistics, etc., in order to improve and make decision-making easier. Moreover, numerous advice, tips, and education, including developing IoT technologies aiming at developing and improving food production.

In Serbia, one quarter of the population works in agriculture, and makes up $10 \%$ of value added in percent of the GDP, $57 \%$ of the entire land area is dedicated to agricultural purposes.[5] Associations, local societies, and organizations are vanishing from the rural areas, making it harder for the manufacturers to place their products on the market, promote them, and enrich their profession. Since 2005, efforts for digitalization, especially projects of e-governance, have been implemented in many fields, but not in agriculture. EU Integrations are strong drivers for the development of ICT in agriculture, which require actions, and are the ones providing the funds for it. "This is explained by the legal obligation set by the EU to operate an integrated information system in relation with the Common Agricultural Policy." Looking ahead, the attention paid to agriculture development and the implementation of ICT in its processes is a matter of the whole world at the moment and, accordingly, the world's common bodies and organizations, such as the United Nations, are doing research in the field across the globe. Some of the advice and conclusions that the Food and Agricultural Organization have come up with are: "The farmer should be in the center of the strategy, which should not be 'forgotten' during the process driven by the governmental authorities and other stakeholders isolated from the 'end users'... the strategy should be planned and implemented to ensure a win-win for farmer and government (and other stakeholders)...The pace of high-tech innovation is increasing in agriculture... for this reason we will need a functional e-strategy on national and international level that may be the pillar of the future farming regulations and sustainable smart agriculture" [5] In addition to many other instructions, it mentions the need to "Stimulate collaboration and knowledge sharing via online communities of practice, including existing regional networks..." What is also noted is that, in order for Member States of the EU to obtain the funds and subsidies within the CAP, they must operate an Inte- grated Administration and Control System (IACS), and fulfill certain conditions such as having computerized and interconnected databases which are used to receive and process aid applications and respective data. Thus it provides for: a unique identification system for farmers, an identification system covering all agricultural areas called land parcel identification system, an identification system for payment entitlements, a system for identification and registration of animals [5]. In an overall review of what is trending, what is evolving, and what has already been done worldwide and in the region, we were able to ascertain the requirements for a country like Serbia, which is still in the development stage. Comparing it with other EU-funded projects focusing on e-governance in the field of agriculture, the following stood out: developing and continuously updating databases useful for the government, providing advice, education, tools, fostering the conditions and opportunities necessary for the manufacturers in agriculture and other stakeholders, and last but not least, developing rural areas in social and infrastructural aspects by connecting people and providing the content and conditions for growth on the local level. With these requirements and existing problems, we adjusted our functionalities

\section{FUNCTIONS AND USER INTERFACE OF EAGRO APPLICATION}

The application is consisted of the following functionalities: registration/login, searching for the offers and products, as well as for people, associations and other users, viewing their profile and connecting with them so that their posts and news would appear on the user's homepage and have one-to-one communication, editing user's profile and personal information, posting events, offers, polls etc., accessing educational materials, subsidies and other opportunities for their business, easy communication and work with the government.

\section{Registration and login}

Only registered users can fully access all information of a profile and fully utilize functionalities of the application. Logging in will be done with a username/e-mail and password, and registration is open to everybody. When creating a profile people will have an option to select the type of profile being created, i.e. is it a community page, a company, a person, or another type of a group. Certain personal information and business in- 
formation will be required, as in name, birthdate, birthplace, e-mail, as well as information like location, land area, capacities, production, equipment, fertilizers and owned certificates or licenses. Depending on the user profile type and on the type of information entered, different information will be required and some proof, reviewed by a governing body, regarding licenses, certificates, land area, etc.

Some of this information will be mandatory to be displayed: name, location, products and certificates. The user will have the option to select how much of other information will be publicly displayed: groups joined, birthplace, birthdate (or founding year), reviews, career highlights and other business information. Sharing a person's ID, passport or social security number will be prohibited. Groups will display information about its central location, admin, members, affiliations with other users or groups, certificates and licenses.

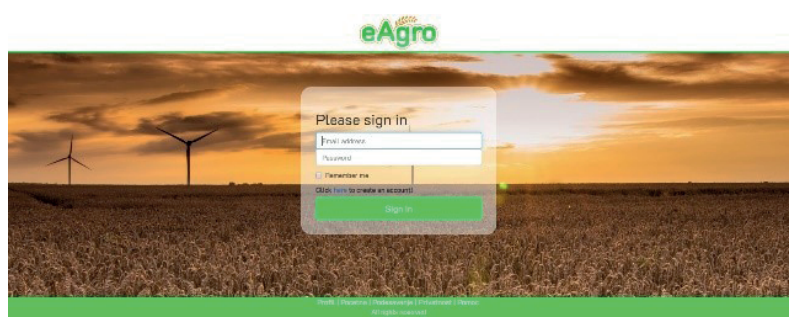

Fig. 1. Registration and login page

View profile, connect and join a group

A profile will have information about its validity, i.e. if its information, private and business, is verified or not. This is made to prevent certain scams, abuse and misinformation. If a user is connected to another profile, or a member of a group, its recent activities and new developments will be displayed on the home page. If a member of a group, notifications about updates will be automatically turned on, and if connected to another profile, notifications will be automatically turned off. These can be features can be disabled or changed at any given point depending on the person's preferences. When trying to contact and message another user, a request to message will be sent to the profile, and the recipient has the option of accepting or declining it. If a user requests to join a group, a notification will be sent to the admin. Users also have the option of reporting or blocking users. Reporting will be allowed for dishonest business, harassment, spam, bots or hacked accounts.

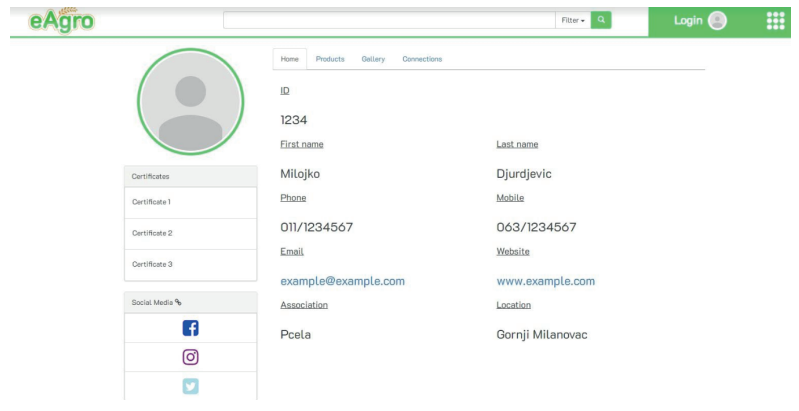

Fig. 2. eAGRO profil page

Post

Posting will enable our users to utilize this platform in multiple ways, like event promotion, offers, renting land, parcels or equipment and polls. Promotion of events is mostly aimed at fairs, festivals, or other (e.g. wine or liquor tasting). Offers for selling, buying or ordering will cover a range of necessities, i.e. seedlings, machinery, fertilizers, food for livestock, land for sale or rent, requests of fruit arching, etc. These posts can also serve for recruitment of workers, especially seasonal work for certain crops, like berries, nuts, grapes and other. Polls can serve as opinions on what the public or other workers, or whoever thinks on certain topics, like preferred types of fertilizers, sharing ideas, gathering opinions and reviews about a past or future event etc.

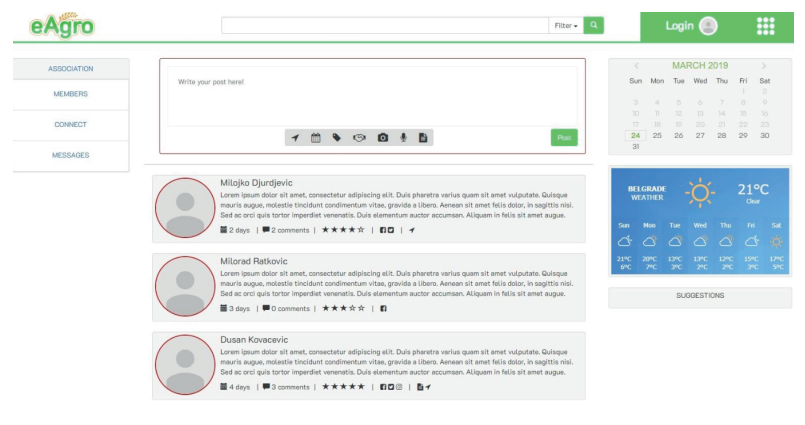

Fig. 3. eAGRO posts

Home page, search and filter

A profile will have information about its validity, i.e. if its information, private and business, is verified or not. This is made to prevent certain scams, abuse and misinformation. If a user is connected to another profile, or a member of a group, its recent activities and new 
developments will be displayed on the home page. If a member of a group, notifications about updates will be automatically turned on, and if connected to another profile, notifications will be automatically turned On his home page a user will be able to scroll through posts from the groups he is a member of and from users he has connected with, where his prioritized pages will be the first one to show up. This information will consist of latest updates, certain posts, buy or sell offers, upcoming events and other information of interest. The home page will also include a weather forecast, a search bar, a notification bar and a calendar. A user will be able to search for anything and utilize the application's filters, such as groups, people, manufacturers, transportation, events, posts, offers, location, products or certificates and licenses. A notification bar will display most important updates, with the first ones to be from the user's local community. The user will have the ability to control the amount of notifications he receives from certain profiles. Concerning the weather forecast, we will be looking to collaborate with certain meteorologists to bring their information onto the website for the people in as high detail as possible. The calendar will contain the user's community upcoming events, as well as events he has marked as interesting or important to him. The user will be able to put his own information into the calendar, which can serve as a reminder and organizer for his own work.

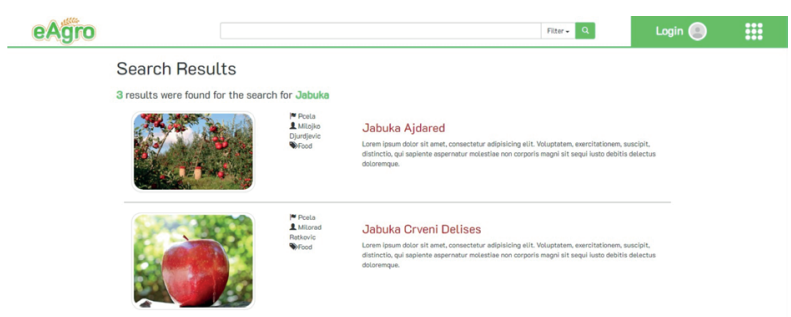

Fig. 4. Different search results in eAGRO application

\section{Education and e-governance}

When it comes to education, some parts of what we intend to provide is intertwined with e-governance. We will provide guides of how to work with the government, how to stay compliant with laws and regulations, how to get certain approvals, licenses and certificates, and inform people on insurance policies. Next we will provide information on how to protect one's production and their work. This will be done with education on storage, on which fertilizers are preferred and recommended, how to protect one's crops from diseases, weeds and other pests. Furthermore, we will promote and provide links to studies and seminars related to the agricultural field. In addition to studies, we will promote and provide links to any kinds of open calls and contests, implement information on standardized prices about their products, and how to potentially acquire subsidies.

Concerning the part of e-governance, we will help expedite the process of gathering information and helping users acquire any sort of necessary documents. We will be connecting users to appropriate governing bodies and allow them to more efficiently finish the job. They will be able to submit requests for all aspects of their work, like acquiring licenses, certificates and insurance, have quality and safety checks of their samples. In addition, they will have the ability to report any sort of problems, like complaints of their local authority or local community, as well as any kind of malicious activity.

\section{Settings}

In settings, user will have a choice to adjust a number of things: priority of connections and groups, notifications, home page, privacy, login information, profile information and blocking. Priority of connection and groups, notifications and home page are pretty selfexplanatory. The user will have the ability to change who he is connected to, which groups he is a member of and whether or not he wants to receive notifications of their activities. The notification settings will give the user the choice of what he wants to be notified about, and how much information he wants to receive in that manner. The home page settings concern whether the user receives only information from people and groups he is affiliated with, but as well as other offers, events and additional information. In his privacy settings the user will have control over what exactly he wishes to display to other members on the web application, who can see his activities and posts, who he can be contacted by and how his profile can be found, for example by searching by name, or by e-mail, or by username, or by location. Login information settings will contain the possibility to change e-mail, password or other important information concerning the user's profile. In profile information settings he will have the ability to add new certificates, licenses, remove expired ones, and edit any other information. Certain changes in profile information will require some proof and oversight by governing bodies, 
just like when registering and creating a profile. Lastly, in the settings for blocking, he will have the ability to remove or add users to his blocked list, as well as block certain users from sending invites to groups and events.

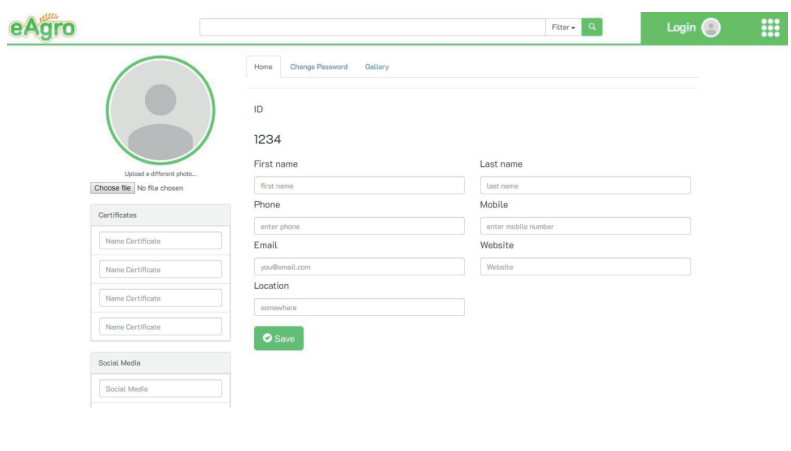

Fig. 5. Settings screen of eAGRO application

\section{ARCHITECTURE OF EAGRO APPLICATION}

eAGRO web application is designed as a standard three-tier client-server application. This is a common choice in developing modern web applications. Typical three-tier web application is consisting of:

- Presentation tier (frontend) - user interface, which is responsible of taking user input and displaying results in a way user can understand.

- Business logic tier (backend) - layer in the middle, responsible of processing user request, making necessary logical decisions and calculations. This layer communicates with both surrounding layers to provide desired functionality.

- Data tier (database) - stores application data, and when requested passes it to the business logic tier for data processing.

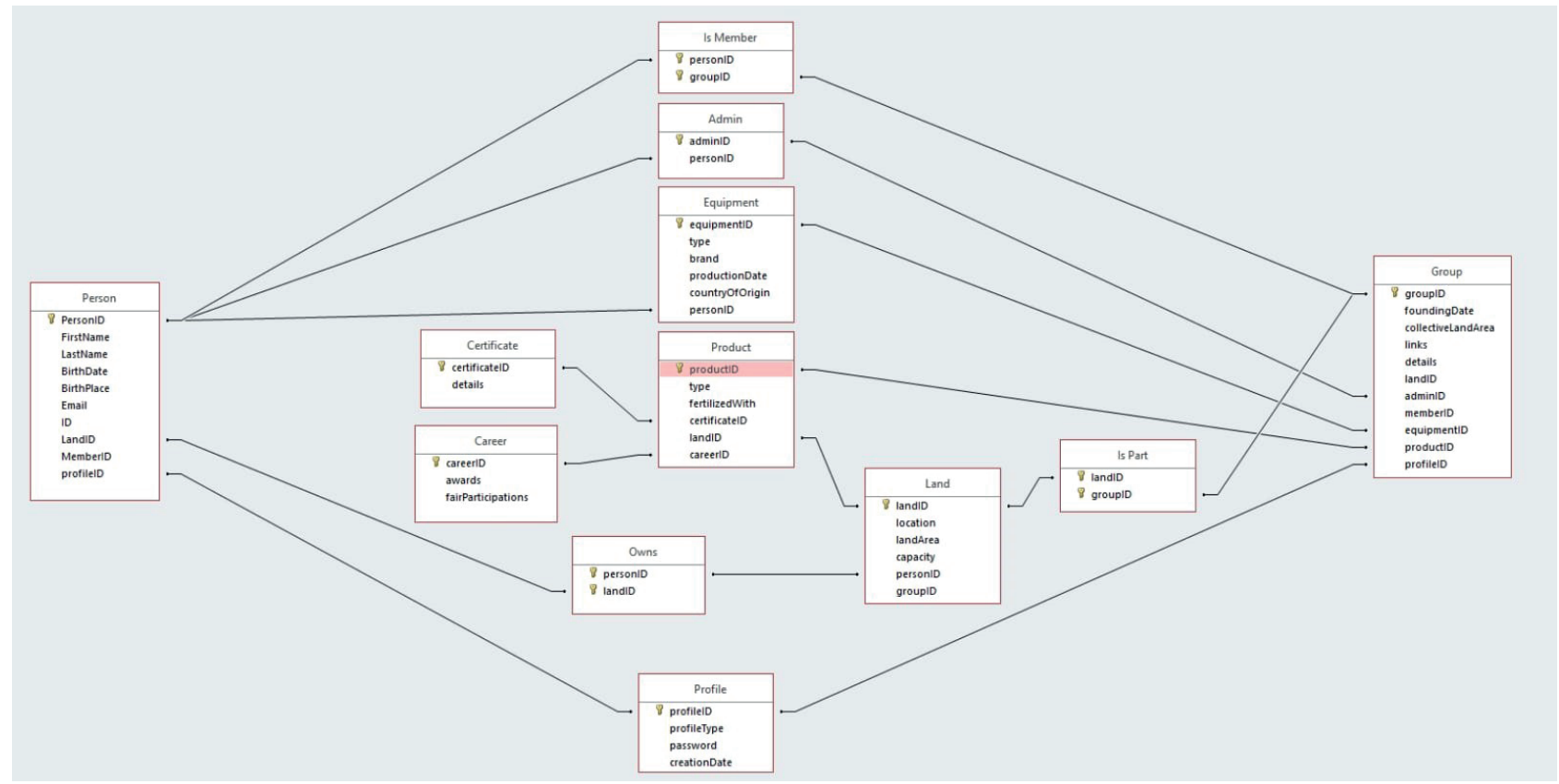

Fig. 6. Data model of eAGRO application

\section{IMPLEMENTATION}

\section{Frontend}

In development of frontend we used HTML, CSS, Bootstrap, JavaScript and jQuery, to provide a modern user interface which will be interactive and attractive to end users. Design of the page was inspired with green color which is traditionally considered as a color of agriculture, and naturally calming.

\section{Backend and database}

Backend was developed as a RESTful web service in Java Spring framework. RESTful web service was chosen as it is generally light weight, easy for maintenance and 
highly scalable. Additionally, it is a common choice for creating API for different types of web applications.

Spring Boot was used for developing backend, as it provides very good support for enterprise web application development. RESTful API was implemented in traditional way, in three layers:

- REST controllers level

- Service level

- Data Access level (DAO level)

REST controllers define the business logic, and provide responses in JSON. With the @RequestMapping annotiation we defined REST Endpoints. Example of the REST controller implementation is given with the following code, which shows UserController.java class. It maps HTTP requests to the route /users. All basic CRUD operations are implemented, including GET (return one user by id and return all users), POST (create new user), PUT (update user with given id), and DELETE (delete user with given id). The other controllers are implemented in similar fashion.

\section{@RestController \\ @RequestMapping("/users") \\ class UsersController \{}

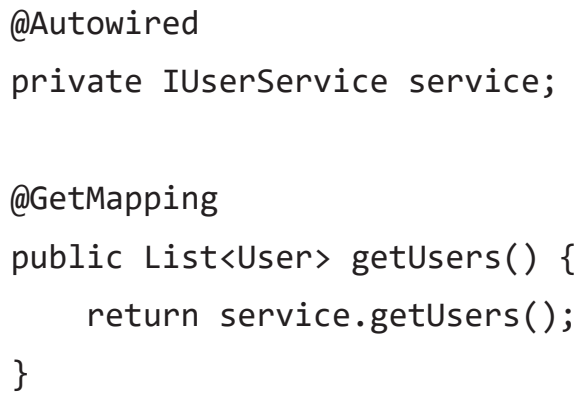

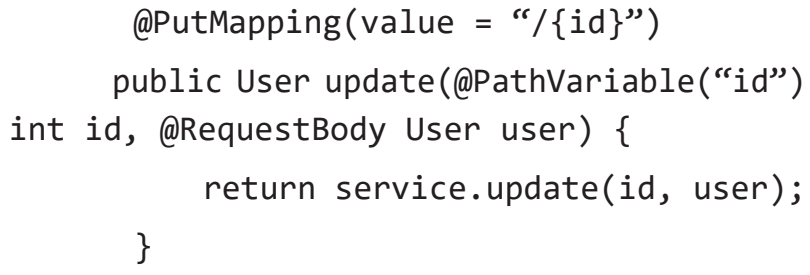

Database was created in MySQL, according to the model shown in figure 6 .

\section{CONCLUSION}

Since agriculture is Serbia's largest branch of economy, we have decided to contribute to its further development in compliance with the existing governmental plans in this area. After our analysis of the status quo and of previous actions taken in other countries, we have developed a uniform solution to many current problems. We constructed the functionalities of the applications according to world trends and the standards of EU integrations, the latter of which primarily focuses on funding for agricultural and governmental development. Our solution ranges from connecting subjects in the agricultural system to increasing information and education levels of the manufacturers, to making and regularly updating databases of the appropriate organizations and bodies, to improving communication between end-users and the government. This project is in the early phase of conception, which includes developing the interactive user-friendly UI/UX frontend components, but which shows great potential for additional functions. Some of the intended features will incorporate business management and risk calculation functionalities, with an overview of statistics and real-time updates. This will allow running a business in agriculture to gain more perspectives and stability, while ensuring further improvement in this branch of the economy. Moreover, we are planning to introduce a new type of user account that would connect all users on a local level, manufacturers, associations, and independent stakeholders alike. This will be designed for the 
better development of rural societies, to provide a space for those individuals who do not wish to be affiliated with any associations, thereby allowing for more accessible collaboration, communication, problem-reporting, and problem-solving. A feature that we will work on as well is the online market/shop, with intention to enable users to place their products on the market in real time. All of this will be realized in the form of mobile application for Android and iOS, besides the already developing web platform.

However, this application has a few potential disadvantages. One of these drawbacks is that this application relies on users adapting this new platform. The application relies on people having an interested in it, and in turn having this online presence in order for it to thrive and achieve all of the intended goals. In addition, some of the older generations, which are a large part of the agricultural community, might find moving to the platform too difficult and filled with too much information, even though we intend to provide a suitable tutorial for new users.

\section{ACKNOWLEDGE TO THE TEAM}

We would like to point out that not all of them who made this happen for Sinteza 2019. are signed above. Big thanks to Dušan Dotlić the developer of Databases and the contributor to the idea development, and to other team members. We would also like to thank our mentor dr. Miodrag Živković for his help and guidance on this project.

\section{REFERENCES}

[1] http://www.momagri.org/UK/momagri-our-issue. html, on 23.3.2019.

[2] http://www.momagri.org/UK/momagri-our-mission.html

[3] https://mapof.ag/what-we-do/

[4] https://ec.europa.eu/agriculture/rural-development-2014-2020_en, on 23.3.2019.

[5] Status of Implementation of e-Agriculture in Central and Eastern Europe and Central Asia: Insights from selected countries in Europe and Central Asia, Food and Agriculture Organization of the United Nations, 2015 